08.3;13.1

\title{
Влияние интерфейса на магнитное состояние в двухслойных пленках системы $\mathrm{Fe}-\mathrm{Bi}$
}

\author{
(ㄱ Г.С. Патрин ${ }^{1,2}$, В.Ю. Яковчук ${ }^{2}$, С.А. Яриков ${ }^{1,2}$, Я.Г. Шиян ${ }^{1,2}$, В.П. Фурдык ${ }^{1}$ \\ ${ }^{1}$ Сибирский федеральный университет, Красноярск, Россия \\ ${ }^{2}$ Институт физики им. Л.В. Киренского, ФИЦ КНЦ СО РАН, Красноярск, Россия \\ E-mail: patrin@iph.krasn.ru
}

Поступило в Редакцию 22 февраля 2019 г.

В окончательной редакции 22 февраля 2019 г.

Принято к публикации 4 марта 2019 г.

\begin{abstract}
Представлены результаты экспериментальных исследований двухслойных пленок в системе $\mathrm{Fe}-\mathrm{Bi}$. Обнаружено, что от очередности напыления магнитного и немагнитного слоев зависят как процесс намагничивания, так и поведение магнитного резонанса. Результаты объясняются образованием сильно анизотропного подслоя наногранулированного железа в пленочной структуре Bi/Fe.
\end{abstract}

DOI: $10.21883 /$ PJTF.2019.10.47754.17750

Интерес к пленочным наноразмерным структурам обусловлен не только фундаментальными проблемами физики конденсированного состояния вещества, но и развивающимися прикладными исследованиями для устройств спинтроники. В связи с этим возникают задачи по разработке новых наноразмерных материалов и поиску эффектов, пригодных для практического использования. В частности, использование в магнитной структуре в качестве немагнитной прослойки полупроводниковых или полуметаллических материалов значительно расширяет функциональные возможности (например, создание спинового мазера [1]). Это позволяет интегрировать в одной структуре как магнитные, так и полупроводниковые свойства исходных материалов [2] и индуцировать новые, не присущие им ранее.

В ряду полупроводниковых и полуметаллических элементов висмут выделяется тем, что он практически не образует химических соединений с $3 d$-металлами [3], что делает его удобным материалом при создании слоистых структур с резкой границей раздела.

В зависимости от технологии получаются либо твердые растворы [4] при больших скоростях и высоких температурах напыления (пленки $\mathrm{Fe}_{x} \mathrm{Bi}_{1-x}$ ), либо пленочные структуры при малых скоростях напыления $(\mathrm{Fe} / \mathrm{Bi})[5]$. В первом случае, как правило, реализуется магнитное состояние типа „спиновое стекло“, а во втором случае спектр проявлений гораздо шире.

Подробнее всего исследованы пленки в системе $\mathrm{Co}-\mathrm{Bi}$. В структуре $[\mathrm{Co} / \mathrm{Bi}]_{19} / \mathrm{Co}[6]$ с суммарной толщиной $<100 \mathrm{~nm}$ и разными толщинами слоев Со и $\mathrm{Bi}$ установлено, что четкой слоистой структуры не получается, а возникает последовательность слоев висмута с вкраплениями гранул кобальта. Авторы объясняют этот результат тем, что в процессе напыления атомы Со пронизывают слои $\mathrm{Bi}$, вызывая смешивание на границе раздела. Подобный результат получен для пленок $\mathrm{MnBi}$ при послойном напылении элементов и последующем отжиге структуры [7]. В трехслойных пленках
$\mathrm{Co} / \mathrm{Bi} / \mathrm{Co}[8]$ с толщиной прослойки $t_{\mathrm{Bi}}=1-30 \mathrm{~nm}$ после отжига получается структура кобальта со случайно распределенными гранулами висмута.

Настоящая работа посвящена исследованию магнитных свойств двухслойных пленок в системе $\mathrm{Fe}-\mathrm{Bi}$ в зависимости от очередности нанесения магнитного и немагнитного слоев.

Пленки были получены методом термического испарения при базовом вакууме $P \sim 10^{-6}$ Torr. В качестве магнитного материала было выбрано железо в силу того, что в нашем случае легко контролировать образование метастабильных модификаций железа, чтобы не затушевывать межслоевое взаимодействие. При напылении для наведения оси легкого намагничивания в плоскости пленки прикладывалось магнитное поле $\sim 16 \mathrm{kA} / \mathrm{m}$. В одном цикле на стеклянные подложки напылялись пленки композиций $\mathrm{Fe} / \mathrm{Fe}, \mathrm{Fe} / \mathrm{Bi}$ и $\mathrm{Bi} / \mathrm{Fe}$. Для всех пленок толщина магнитного слоя составляла $t_{\mathrm{Fe}} \approx 10 \mathrm{~nm}$, а толщины висмута были $t_{\mathrm{Bi}}=15 \mathrm{~nm}$. Величина $t_{\mathrm{Fe}}$ была выбрана из тех соображений, чтобы она была довольно малой, но в то же время достаточной для того, чтобы намагниченность магнитного слоя не менялась при флуктуациях его толщины.

Толщины слоев определялись методами рентгеновской спектроскопии. Электронно-микроскопические измерения показали, что слои являются сплошными по площади и их состав соответствует номинальному. Никаких следов наличия соединений $3 d$-металл-висмут не обнаружено. Присутствия окислов железа также не обнаружено. Структура поверхности пленок исследовалась на атомном силовом микроскопе Veeco MultiMode (разрешение $1 \mathrm{~nm}$ ). Установлено, что высота шероховатости поверхности не превышает $2.5 \mathrm{~nm}$. Намагниченность измерялась на СКВИД-установке MPMS-XL. Магнитное поле лежало в плоскости пленки и при всех измерениях было направлено вдоль легкой оси. Для измерения резонансных свойств использовался ЭПР-спектрометр 


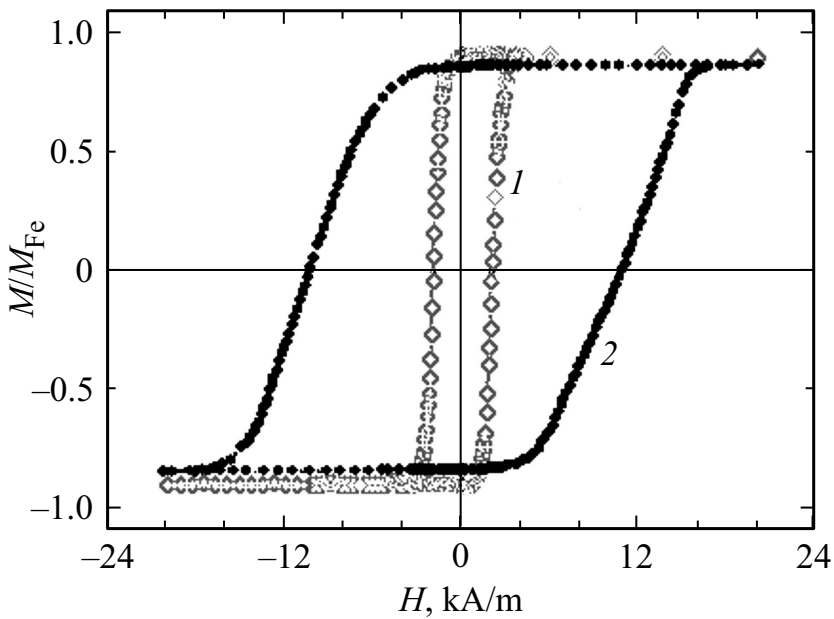

Рис. 1. Петли гистерезиса двухслойных пленок $\mathrm{Fe} / \mathrm{Bi}(1)$, $\mathrm{Bi} / \mathrm{Fe}(2)$ при $T=300 \mathrm{~K}$.

„Bruker E $500 \mathrm{CW}$ EPR“, действующий на частоте $f_{\mathrm{MWF}}=9.48 \mathrm{GHz}$.

При измерении магнитных свойств было обнаружено, что форма кривой намагничивания двухслойной пленки зависит от очередности нанесения магнитного и немагнитного полуметаллического слоев. На рис. 1 приведены кривые намагничивания пленок $\mathrm{Fe} / \mathrm{Bi}$ (1) и $\mathrm{Bi} / \mathrm{Fe}(2)$, максимальная величина намагниченности нормирована на намагниченность насыщения реперной пленки чистого железа. Видно, что намагниченность насыщения практически одинаковая для обеих пленок, однако коэрцитивные силы пленок со слоем висмута „сверху“ (структура 1) и „снизу“ (структура 2) слоя железа существенно различаются (примерно в 5 раз). В нашем случае намагниченность лежит в плоскости пленки вдоль легкой оси, а это значит, что и в структуре 1 , и в структуре 2 поле размагничивания одно и то же. Как известно [9], коэрцитивная сила пропорциональна магнитной анизотропии, а это дает основание считать, что на границе раздела ферромагнетик-полуметалл возникает дополнительная интерфейсная анизотропия.

Дополнительные данные были получены при изучении магниторезонансных свойств. На рис. 2 приведены спектры СВЧ-поглощения исследованных пленок. На рис. 2, $a$ приведен спектр для реперной пленки чистого железа. Видно, что напыление второго слоя из висмута по-разному изменяет спектр магнитного резонанса в зависимости от очередности напыления магнитного и немагнитного слоев (рис. $2, b$ и $c$ ). Наиболее сильное изменение наблюдается для пленки композиции $\mathrm{Bi} / \mathrm{Fe}$. На рис. 3, $a$ представлены температурные зависимости резонансных полей. Как известно [10], для магнитной пленки зависимость резонансной частоты $(\omega)$ от магнитного поля с учетом анизотропии формы и магнитной анизотропии дается выражением

$$
(\omega / \gamma)^{2}=H\left(H+H_{M}+H_{A}\right)
$$

где $H_{M}=4 \pi M-$ поле размагничивания, $H_{A}=2 K /(t M)-$ поле анизотропии, $K-$ константа анизотропии, $t$ - толщина магнитного слоя, $\gamma-$ гиромагнитное отношение. Поскольку величина насыщения намагниченности одинакова для всех пленок (рис. 1), величина $H_{M}$ также является одинаковой для всех пленок. Тогда из формулы (1) следует, что от очередности напыления
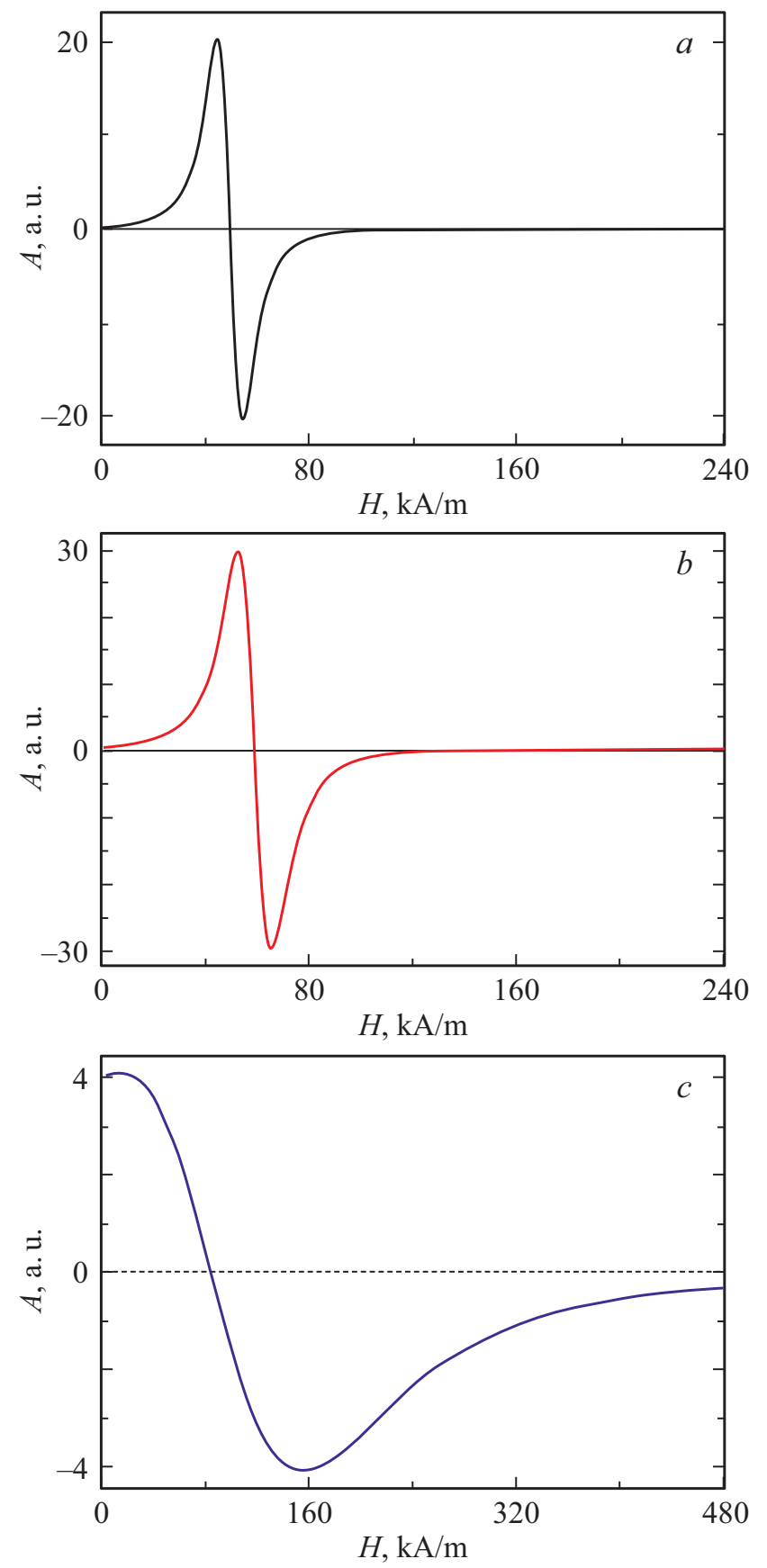

Рис. 2. Спектры СВЧ-поглощения пленок $\mathrm{Fe} / \mathrm{Fe}(a), \mathrm{Fe} / \mathrm{Bi}(b)$, $\mathrm{Bi} / \mathrm{Fe}(c)$ при $T=300 \mathrm{~K}$. Внешнее магнитное поле направлено вдоль легкой оси в плоскости. 

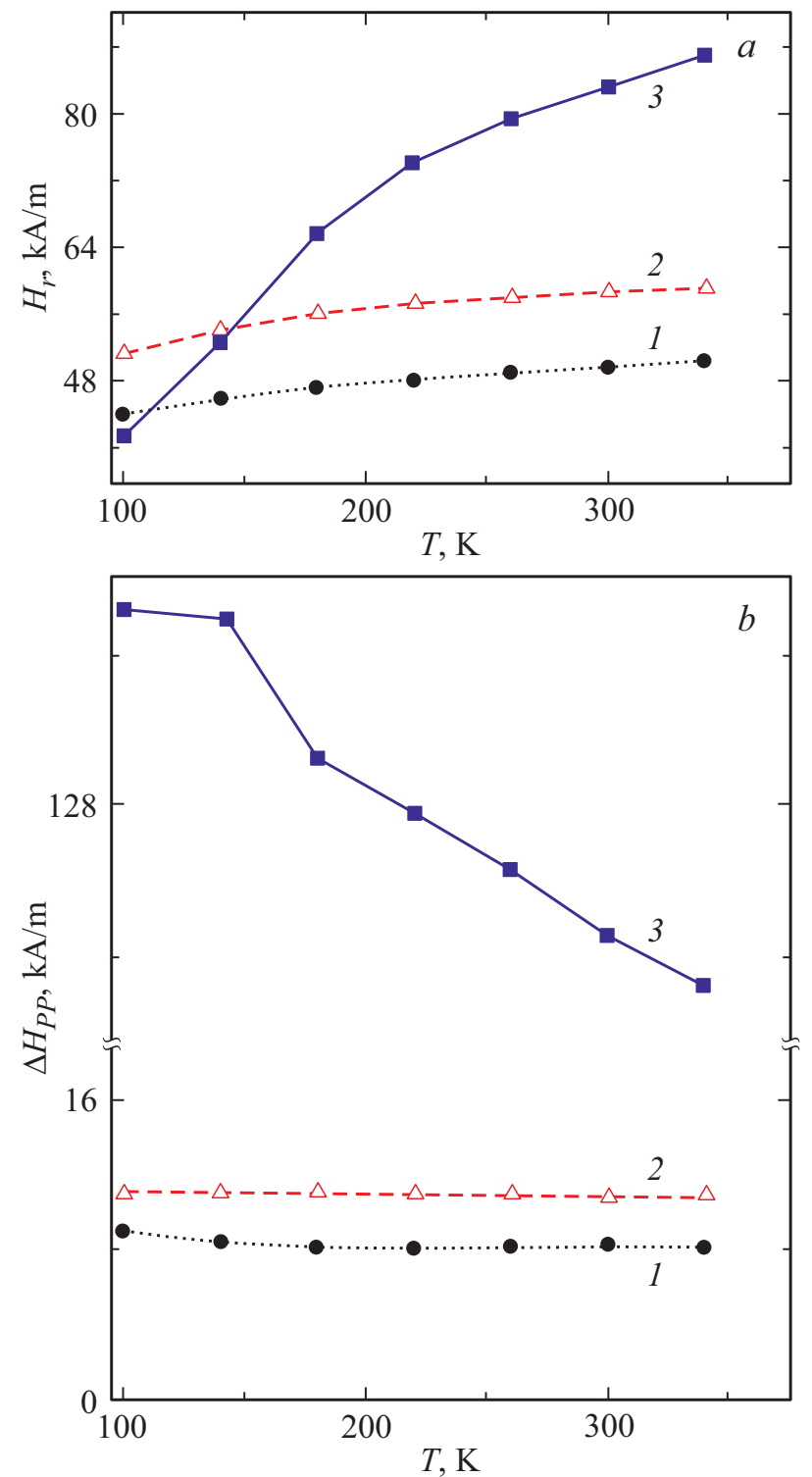

Рис. 3. Температурные зависимости параметров магнитного резонанса. $a-$ резонансное поле, $b-$ ширина резонансной кривой. $1-\mathrm{Fe} / \mathrm{Fe}, 2-\mathrm{Fe} / \mathrm{Bi}, 3-\mathrm{Bi} / \mathrm{Fe}$.

слоев зависит поле анизотропии. Еще сильнее различие проявляется в температурных зависимостях ширины линии $\Delta H_{P P}$ (рис. $\left.3, b\right)$. Ширина линии для пленки $\mathrm{Bi} / \mathrm{Fe}$ при азотных температурах почти на порядок больше, чем $\Delta H_{P P}$ для реперной пленки железа и пленки $\mathrm{Fe} / \mathrm{Bi}$.

Зависимость магнитных свойств пленочных структур от состояния интерфейса наблюдалась и раньше, например в системе Ni-Ge [11]. На границе раздела из-за перемешивания элементов образуется германид никеля, он проявляется тем сильнее, чем тоньше слой никеля. А в структуре $\mathrm{Si}(100) / \mathrm{Cu}(1000) / \mathrm{Ni}(60) / \mathrm{Co} / \mathrm{Cu}(30)$ [12] происходит ориентационный переход типа легкая ось-легкая плоскость в зависимости от толщины слоя кобальта. Здесь также главную роль играет состояние интерфейса $\mathrm{Co}-\mathrm{Ni}$, где анизотропия кобальта меняется вследствие изменения его ближайшего окружения.

Однако в нашем случае на границе раздела магнитного и немагнитного слоев никаких соединений не образуется [3]. Можно предположить, что происходит реконструкция железа и вследствие этого изменение магнитного состояния. Здесь уместно вспомнить, что температура плавления железа равна $\sim 1812 \mathrm{~K}$, а температура плавления висмута всего $\sim 545 \mathrm{~K}$. В том случае, когда нижним слоем является железо (двухслойная структура $\mathrm{Fe} / \mathrm{Bi}$ ), ионы висмута, достигающие поверхности железа при напылении, имеют относительно невысокую энергию и не проникают глубоко в толщу $\mathrm{Fe}$, т.е. на интерфейсе образуется достаточно резкая граница раздела элементов, где изменяется геометрия окружения железа. Эта часть железа и создает небольшую дополнительную магнитную анизотропию, что подтверждается небольшим различием резонансных полей и ширин линий для пленок $\mathrm{Fe} / \mathrm{Fe}$ и $\mathrm{Fe} / \mathrm{Bi}$ (рис. 3, кривые 1 и 2).

Ситуация кардинально меняется для структуры $\mathrm{Bi} / \mathrm{Fe}$. Здесь сильно разогретые высокоэнергетические ионы железа падают на слой висмута, который является легкоплавким. Железо проникает достаточно глубоко в толщину висмутового слоя. В результате образуются наноразмерные гранулы железа. Известно, что в наногранулированном состоянии частицы железа обладают гораздо большей анизотропией. Например [13], для частиц диаметром $d \approx 5.5 \mathrm{~nm}$ константа анизотропии $K \approx 1.3 \cdot 10^{5} \mathrm{~J} / \mathrm{m}^{3}$, тогда как для объемной фазы (bcc) она равна $K \approx 4.8 \cdot 10^{4} \mathrm{~J} / \mathrm{m}^{3}$. Таким образом, для пленки $\mathrm{Bi} / \mathrm{Fe}$ образуется дополнительная подсистема сильно анизотропных гранул железа, растворенных в висмуте, которая обменно связана со слоем железа. После напыления структуры в процессе ее охлаждения в магнитном поле дополнительно наводится анизотропия, которая существенно влияет как на процессы намагничивания, так и на динамику магнитной системы (рис. 3, кривые 3).

Полученные результаты являются важными при создании многослойных структур с полуметаллической прослойкой висмута. В этом случае необходимо учитывать неэквивалентность магнитных слоев и наличие дополнительного источника интерфейсной анизотропии. Более детальное исследование особенностей влияния гранулированной подсистемы железа на магнитные свойства многослойных структур в системе $\mathrm{Fe}-\mathrm{Bi}$ и спиновую динамику будет представлено в другой работе.

\section{Финансирование работы}

Исследования проведены при финансовой поддержке Российского фонда фундаментальных исследований (грант № 18-02-00161-a). 


\section{Список литературы}

[1] Виглин Н.А., Устинов В.В., Осипов В.В. // Письма в ЖЭТФ. 2007. Т. 86. В. 3. С. 221-225.

[2] Захарченя Б.П., Коренев В.Л. // УФН. 2005. Т. 175. № 6. C. $629-635$.

[3] Денисов В.М., Белоусова Н.В., Моисеев Г.С., Бахвалов С.Г., Истомин С.А., Пастухов Э.А. Висмутсодержащие материалы. Строение и физико-химические свойства. Екатеринбург: УрО РАН, 2000. 526 с.

[4] Chen Q.M., Cui F.Z., Fan Y.D., Li H.D. // J. Appl. Phys. 1988. V. 63. N 7. P. $2452-2453$.

[5] Cui F.Z., Fan Y.D., Wang Y., Vredenberg A.M., Draaisma H.J.G., Xu R. // J. Appl. Phys. 1990. V. 68. N 2. P. 701-704.

[6] Hozumi T., Le Clair P., Mankey G., Mewes C., SepehriAmin H., Hono K., Suzuki T. // J. Appl. Phys. 2014. V. 115. N 17. P. 17A737 (1-3).

[7] Unger W.K., Stolz M. // J. Appl. Phys. 1971. V. 42. N 3. P. $1085-1089$.

[8] Vorobiova S.I., Shutylieva O.V., Pazukha I.M., Chornous A.M. // Eur. Phys. J. Plus. 2016. V. 131. N 6. P. 203 (1-7).

[9] Chikazumi S. Physics of ferromagnetism. 2nd ed. Oxford University Press, 2009. 497 p.

[10] Heinrich B. Ferromagnetic resonance in ultrathin film structures // Ultrathin magnetic structures II. Measurement techniques and novel magnetic properties / Eds B. Heinrich, J.A.C. Bland. Berlin: Springer, 2000. P. 195-222.

[11] Эдельман И.С., Патрин Г.С., Великанов Д.А., Черниченко А.В., Турпанов И.А., Бондаренко Г.В. // Письма в ЖЭТФ. 2008. Т. 87. В. 5. С. 310-313.

[12] Lee J., Lauhoff G., Bland J.A.C. // Phys. Rev. B. 1997. V. 56. N 10. P. R5728-R5731.

[13] Mehdaoui B., Meffre A., Lacroix L.-M., Carrey J., Lachaize S., Respaud M., Gougeon M., Chaudret B. // J. Appl. Phys. 2010. V. 107. N 9. P. 09A324 (1-3). 